\title{
PENGARUH BERBAGAI METODE PEMATAHAN DORMANSI BIJI TERHADAP DAYA KECAMBAH DAN PERTUMBUHAN VEGETATIF Mucuna bracteata
}

\author{
Muhammad Hamzah \\ Peneliti di Department Riset PT. Panca Surya Garden, First Resources Ltd \\ Korespondensi penulis, \\ email: muhammad.hamzah@first-resources.com
}

\begin{abstract}
ABSTRAK
Mucuna bracteata merupakan tanaman merambat dengan pertumbuhan vegetatif yang sangat cepat karena memiliki sistem perakaran yang dalam, namun permasalahan dalam proses pembibitan tanaman ini adalah pematahan dormansi biji. Mucuna memiliki kulit biji yang tebal, keras dan kedap yang menjadi penghalang mekanis masuknya air atau gas sehingga proses imbibisi sulit terjadi. Pematahan dormansi pada biji Mucuna bertujuan untuk meningkatkan daya kecambah serta mengevaluasi pertumbuhan vegetatif awal di pembibitan. Penelitian dilakukan di areal pembibitan PT. PSG jalan Kubang Raya, Kab. Kampar-Riau pada bulan Maret sampai Juni 2014 menggunakan Rancangan Acak Kelompok 2 Faktorial dengan 3 ulangan. Faktor pertama adalah skarifikasi (S), yaitu S1 dilakukan skarifikasi pada biji dan S2 tidak dilakukan skarifikasi. Faktor kedua adalah perbedaan suhu, lama waktu dan jenis air perendaman $(\mathrm{P})$, yaitu $\mathrm{P} 1$ air suhu $85^{\circ} \mathrm{C} 60$ menit, $\mathrm{P} 2$ air suhu $85^{\circ} \mathrm{C} 120$ menit, $\mathrm{P} 3$ air suhu $90^{\circ} \mathrm{C} 60$ menit, $\mathrm{P} 4$ air suhu $90^{\circ} \mathrm{C} 120$ menit, $\mathrm{P} 5 \mathrm{H}_{2} \mathrm{SO}_{4} 30$ menit, $\mathrm{P} 6 \mathrm{H}_{2} \mathrm{SO}_{4} 60$ menit dan P7 aquadest 60 menit. Parameter yang diamati antara lain daya kecambah, tinggi tanaman, jumlah daun, warna daun dan jumlah cabang. Hasil penelitian menunjukkan bahwa kombinasi perlakuan perendaman biji dengan $\mathrm{H}_{2} \mathrm{SO}_{4}$ selama 60 menit tanpa skarifikasi menjadi kombinasi dengan rerata daya kecambah tertinggi sedangkan pertumbuhan vegetatif seluruh kombinasi perlakuan menunjukkan keragaan fenotipe yang sama.
\end{abstract}

Kata Kunci: Mucuna bracteta, dormansi, skarifikasi, daya kecambah dan vegetatif

\section{PENDAHULUAN}

Penanaman kacangan penutup tanah merupakan alternatif dalam proses budidaya kelapa sawit yang bermanfaat sebagai mulsa hidup untuk mngendalikan erosi, menekan tumbuhnya gulma, menyumbang sejumlah besar bahan organik seperti nitrogen dan fosfor. Pada saat in jenis kacangan penutup tanah yang relatif baru diperkenalkan di Indonesia adalah Muсuna bracteata. Mucuna merupakan tanaman merambat dengan pertumbuhan yang sangat cepat, memiliki perakaran yang dalam dan berdaun lebar (Siagian, 2003). Selain Mucuna, jenis kacangan lainnya yang sering ditanam disela penanaman kelapa sawit antara lain Pueraria javanica, P. Phaseoloides, Centrosema pubescens, Calopogonium caeruleum, Calopogonium mucunoides (Chua, et al. 2007).

Mucuna bracteata memiliki kulit yang keras sehingga sulit untuk berkecambah sehingga diperlukan metode untuk mematahkan masa dormansi/istirahat baik dengan cara fisik, mekanis maupun kimia. Perlakuan fisik dilakukan dengan menghilangkan kulit benih/testa yang lebih dikenal dengan metode skarifikasi. Proses skarifikasi dilakukan agar embrio dapat segera tumbuh tanpa hambatan karena air dan gas akan mampu masuk kedalam biji sehingga proses imbibisi dapat terjadi. Namun dalam kenyataannya tidak akan mudah terjadi terutama karena ukuran biji yang sangat kecil, kulit atau testa sangat keras dan liat. Hal inilah yang menyebabkan perbanyakan generatif Mucuna bracteata sulit dilakukan dan apabila dilakukan penanaman tanpa proses pematahan dormansi terlebih dahulu maka persentase perkecambahan hanya mencapai $12 \%$ (Siagan dan Tistama, 2005).

Permasalahan dormansi biji ini menyebabkan pembatasan struktural terhadap perkecambahan sehingga menjadi penghalang mekanis masuknya air dan gas. Tebalnya lapisan kulit biji ini disebabkan karena permukaan lapisan kulitnya dilapisi sel-sel serupa polisade 
yang memiliki lapisan lilin dari bahan kutikula (Sutopo, 2002). Untuk mengatasi hal ini maka diperlukan perlakuan fisik seperti skarifikasi/menghilangkan sebagian testa, perlakuan mekanis dengan perendaman air panas pada suhu tinggi $\left(85^{\circ} \mathrm{C}\right.$ dan $\left.90^{\circ} \mathrm{C}\right)$ dan perlakuan kimia dengan cara perendaman dengan asam sulfat $\left(\mathrm{H}_{2} \mathrm{SO}_{4}\right)$ untuk meningkatkan daya kecambah biji serta pertumbuhan vegetatif Mucuna bracteata

\section{METODOLOGI PENELITIAN}

Penelitian ini dilaksanakan di areal pembibitan PT. Panca Surya Garden - First Resources Ltd jalan Kubang Raya, Kab. Kampar - Riau pada bulan Maret sampai Juni 2014. Penelitian ini menggunakan Rancangan Acak Kelompok (RAK) 2 Faktorial dengan 3 ulangan. Faktor pertama adalah perlakuan skarifikasi (S) pada dua taraf, yaitu S1: dilakukan skarifikasi pada biji dan S2: tidak dilakukan skarifikasi pada biji. Faktor kedua adalah perbedaan suhu, lama waktu dan jenis air perendaman $(\mathrm{P})$ dengan 7 taraf, yaitu P1: perendaman dengan air panas suhu $85^{\circ} \mathrm{C} 60$ menit, $\mathrm{P} 2$ : perendaman dengan air suhu $85^{\circ} \mathrm{C}$ selama 120 menit, P3: perendaman dengan air suhu $90^{\circ} \mathrm{C}$ selama 60 menit, P4: perendaman dengan air suhu $90^{\circ} \mathrm{C}$ selama 120 menit, $\mathrm{P} 5$ : perendaman dengan air $\mathrm{H}_{2} \mathrm{SO}_{4}$ selama 30 menit, P6: perendaman dengan air $\mathrm{H}_{2} \mathrm{SO}_{4}$ selama 60 menit dan P7: perendaman dengan aquadest selama 60 menit. Selanjutnya dilakukan analisis ragam menggunakan uji perbandingan ganda DNMRT pada taraf kepercayaan $5 \%$.

Prosedur penelitian di Laboratorium diawali dengan pemilihan atau seleksi biji Mucuna bracteata yang akan dijadikan bahan tanam berdasarkan ukuran dan struktur biji yaitu ukuran biji yang relatif sama besar, struktur utuh dan kulit biji tidak rusak. Kemudian pengelompokkan biji berdasarkan perlakuan penelitian dan diletakkan ke media perendaman (cawan petri). Siapkan air perendaman yaitu air dengan suhu $85^{\circ} \mathrm{C}$, suhu $90^{\circ} \mathrm{C}$ menggunakan hot plat and sterer, setelah 30 menit ukur suhu menggunakan thermometer. Apabila suhu pada thermometer telah menunjukkan angka tujuan $\left(85^{\circ} \mathrm{C}\right.$ dan $\left.90^{\circ} \mathrm{C}\right)$ maka hentikan pemanasan dan segera dilakukan perendaman biji sesuai perlakuan pada metode perendaman (waktu perendaman disesuaikan).

Perlakuan perendaman dengan asam sulfat $\left(\mathrm{H}_{2} \mathrm{SO}_{4}\right)$ dilakukan dengan perhitungan sebagai berikut: 70/97 x $100 \mathrm{ml}$ menghasilkan 72,16 ml $\mathrm{H}_{2} \mathrm{SO}_{4}$. Angka 70 menunjukkan konsentrasi/kepekatan larutan yang akan dibuat sedangkan angka 97 merupakan konsentrasi/kepekatan asam sulfat murni dan 100 merupakan volume/jumlah larutan perendaman yang akan dibuat. Sehingga untuk perendaman menggunakan $\mathrm{H}_{2} \mathrm{SO}_{4}$ sebanyak 100 $\mathrm{ml}$ dilakukan dengan cara melarutkan 72,16 ml asam sulfat ditambah dengan $27,84 \mathrm{ml}$ aquadest. Untuk perlakuan skarifikasi, kulit biji dipotong menggunakan gunting kecil dan dikombinasikan dengan perlakuan lainnya sesuai metode penelitian.

Prosedur penelitian di lapangan dimulai dengan persiapan tanah pada media penanaman biji, tanah yang digunakan merupakan lapisan atas/top soil yang telah diayak menggunakan saringan tanah berukuran $1 \times 1 \mathrm{~cm}^{2}$, kemudian dicampur dengan pupuk rock phospat/RP sebagai pupuk dasar sebanyak 20 gram/polibeg. Tanah hasil ayakan yang telah dicampur pupuk RP dimasukkan kedalam polibeg berukuran $15 \times 20 \mathrm{~cm}^{2}$. Biji yang telah dilakukan perlakuan sesuai perlakuan penelitian selanjutnya ditanam di medium polibeg dengan kedalaman $2 \mathrm{~cm}$, selanjutnya dilakukan proses pemeliharaan tanaman meliputi penyiraman (pagi dan sore hari), pengendalian gulma disekitar tanaman dilakukan secara manual (mekanis/pencabutan), pemupukan dilakukan satu bulan setelah penanaman dengan cara mensuspensikan pupuk Npk 15-15-6-4 didalam air dengan dosis 170 gram per 18 liter air untuk 400 tanaman.

Parameter penelitian yang diamati antara lain a) persentase daya berkecambah biji pada saat 14 hari setelah tanam, b) tinggi tanaman (cm) dilakukan pada saat bibit berumur 45 hari, c) jumlah helaian daun yang tercipta (helai) dilakukan pada saat bibit berumur 45 hari, d) warna daun menggunakan indikator color chart dilakukan pada saat bibit berumur 45 hari, dan e) 
jumlah tangkai daun yang terbentuk (cabang) dilakukan pada saat bibit berumur 45 hari

\section{HASIL DAN PEMBAHASAN}

Data pada Gambar 4 menunjukkan bahwa perlakuan skarifikasi dengan berbagai perbedaan suhu, lama waktu dan jenis air perendaman memperlihatkan persentase daya kecambah yang relatif sama, namun perlakuan kombinasi antara skarifikasi yang direndam air panas suhu $90^{\circ} \mathrm{C}$ selama 120 menit dan skarifikasi + perendaman dengan air $\mathrm{H}_{2} \mathrm{SO}_{4}$ selama 60 menit memiliki persentase daya kecambah tertinggi $(16 \%)$.

\section{Daya Berkecambah}

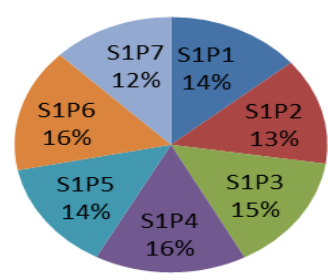

Gambar 1. Persentase daya berkecambah biji perlakuan skarifikasi dengan berbagai perbedaan suhu, lama waktu dan jenis air perendaman

Data pada Gambar 5 memperlihatkan bahwa perbedaan perlakuan pematahan dormansi biji menunjukkan bahwa perendaman dengan air $\mathrm{H}_{2} \mathrm{SO}_{4}$ selama 60 menit tanpa perlakuan skarifikasi biji menjadi perlakuan dengan rerata persentase daya berkecambah tertinggi dibandingkan kombinasi perlakuan lainnnya.

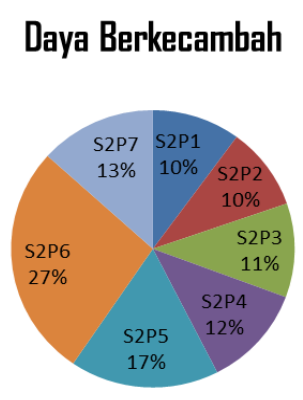

Gambar 2. Persentase daya berkecambah biji perlakuan tanpa skarifikasi dengan berbagai perbedaan suhu, lama waktu dan jenis air perendaman
Sutopo (2002) menyatakan bahwa perlakuan perendaman dengan bahan kimia seperti perendaman dengan asam sulfat $\mathrm{H}_{2} \mathrm{SO}_{4}$ bertujuan untuk melunakkan kulit benih sehingga mempermudah masuknya air dan oksigen kedalam biji yang sangat diperlukan dalam proses imbibisi agar perkecambahan dapat berjalan dengan baik. $\mathrm{H}_{2} \mathrm{SO}_{4}$ bersifat melunakkan dan meregangkan testa sehingga merangsang respirasi untuk perkecambahan karena reaksi asam akan melunakkan lamella tengah jaringan sehingga jaringan menjadi lunak dan pertukaran gas $\mathrm{CO}_{2}$ dan $\mathrm{O}_{2}$ berjalan dengna baik yang akhirnya akan memudahkan plumula dan radikula tumbuh (Hartutiningsih dan Utami, 1999).Perlakuan perendaman dengan asam sulfat menunjukkan hasil terbaik apabila dikombinasikan dengan perlakuan tanpa skarifikasi, hal ini dapat terlihat pada kombinasi antara $\mathrm{S} 2 \mathrm{P} 6$ (perendaman $\mathrm{H}_{2} \mathrm{SO}_{4}$ selama 60 menit tanpa perlakuan skarifikasi biji) sebesar $27 \%$ lebih tinggi dibandingkan perlakuan S1P6 (perendaman $\mathrm{H}_{2} \mathrm{SO}_{4}$ selama 60 menit dengan perlakuan skarifikasi biji).Sejalan dengan hasil penelitian yang dilaporkan oleh Sulaiman dan Gozali (2004) bahwa perendaman dengan bahan kimia seperti $\mathrm{H}_{2} \mathrm{SO}_{4} / \mathrm{KNO}_{3} /$ Asam Giberallin merupakan perlakuan terbaik untuk tujuan pematahan daya berkecambah biji Mucuna bracteata dibandingkan perlakuan fisik dan mekanik lainnya.

Informasi menarik terlihat pada perlakuan asam sulfat yang dilakukan pengelupasan kulit biji, dimana persentase daya berkecambahnya lebih rendah dibandingkan tanpa skarifikasi.Hal ini diduga karena perlakuan perendaman dengan asam sulfat telah menyebabkan kulit biji terkelupas dan melunak sehingga apabila sebelumnya dilakukan perlakuan skarifikasi pada biji tersebut maka akan menyebabkan kerusakan bagian didalam biji (embrio biji) yang akhirnya akan membuat biji tidak mampu mengangkat kotiledon untuk muncul diatas permukaan tanah karena embrio tidak aktif lagi.Hipotesa lainnya adalah ketika biji menyentuh cairan asam sulfat maka akan menyebabkan kekuatan biji/vigoritas kecambah tidak berjalan optimal.Mugnisjah dan Setiawan 
(1990) menyatakan bahwa benih berviabilitas tinggi ditunjukkan dengan adanya daya berkecambah lebih besar dengan kecepatan berkecambah yang tinggi.Pada benih yang penyerapan airnya lebih mudah, umumnya juga akan diikuti dengan kemudahan masuknya senyawa lainnya dalam proses perkecambahan biji.

Tabel 1. Parameter pertumbuhan vegetatif bibit Mucuna bracteata

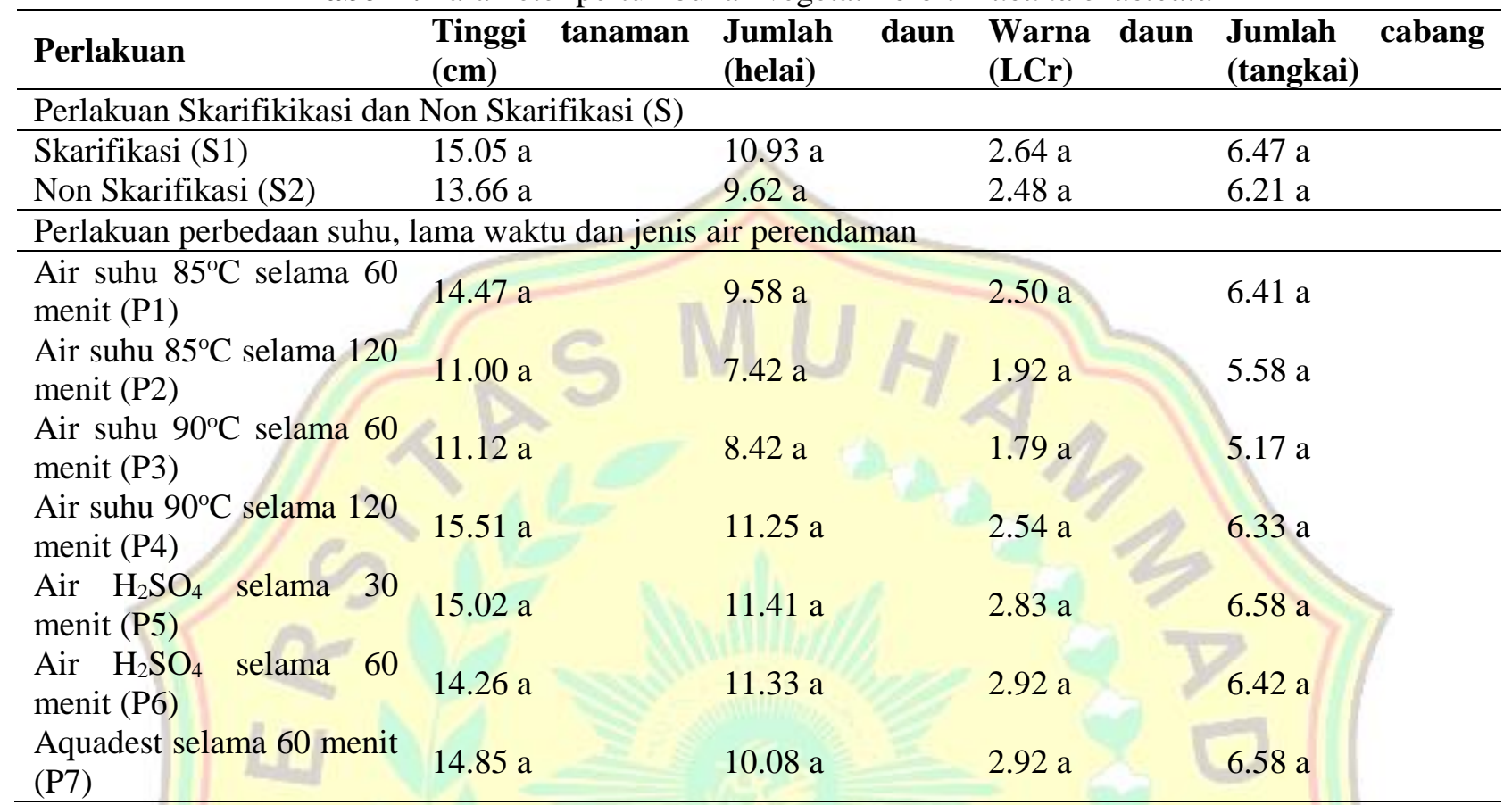

Angka yang diikuti huruf kecil yang sama pada kolom yang sama tidak berbeda nyata menurut uji perbandingan ganda DNMRT taraf $5 \%$.

Berdasarkan data pada Tabel 1 terlihat bahwa perlakuan berbagai metode pematahan dormasi biji Mucuna bracteata berpengaruh tidak nyata terhadap pertumbuhan vegetatif awal bibit.Hal ini ditunjukkan pada perlakuan mekanis seperti dengan metode skarifikasi dan tanpa skarifikasi dimana tidak menunjukkan perbedaan tinggi tanaman, banyaknya jumlah helaian daun yang tercipta, warda daun yang ada serta jumlah tangkai cabang yang terbentuk.Hal yang sama terlihat pada perlakuan fisik seperti perendaman dengan air panas suhu $85^{\circ} \mathrm{C}$ dan $90^{\circ} \mathrm{C}$ baik yang direndam selama 60 menit dan 120 menit jugatidak menunjukkan perbedaan fenotipe pertumbuhan vegetatif bibit. Perlakuan kimia yang dilakukan dengan larutan asam sulfat pada konsentrasi kepekatan $70 \%$ juga tidak menunjukan pengaruh yang berbeda untuk penambahan tinggi, jumlah daun, warna daun dan jumlah tangkai daun yang ada. Hal ini disebabkan karena larutan asam sulfat hanya bertujuan untuk mematahkan dormansi biji dan tidak diperuntukkan dalam meningkatkan pertumbuhan vegetatif bibit. Hardianti et al. (2014) menjelaskan bahwa perlakuan pemberian asam giberalin $300 \mathrm{pm}$ berpengaruh terhadap pertumbuhan vegetatif bibit namun perlakuan fisik dan mekanis tidak berpengaruh nyata untuk seluruh kombinasi perlakuan.

\section{KESIMPULAN}

Berdasarkan hasil penelitian ini dapat disimpulkan bahwa perlakuan perendaman biji Mucuna bracteata menggunakan larutan asam sulfat $\left(\mathrm{H}_{2} \mathrm{SO}_{4}\right)$ selama 60 menit tanpa skarifikasi biji merupakan kombinasi terbaik dalam proses pematahan dormansi biji dengan rerata persentase daya kecambah tertinggi dibandingkan kombinasi lainnya sedangkan pertumbuhan vegetatif bibit (tinggi tanaman, 
jumlah daun, warna daun dan jumlah cabang) tidak berbeda nyata pada seluruh kombinasi perlakuan pematahan dormansi (fisik, mekanis dan kimia). Untuk itu, perlu dilakukan penelitian lanjutan agar didapatkan konsentrasi kepekatan asam sulfat $\left(\mathrm{H}_{2} \mathrm{SO}_{4}\right)$ yang tepat dengan lama waktu perendaman yang lebih singkat sebagai alternatif metode pematahan dormansi biji Mucuna bractetata.

\section{DAFTAR PUSTAKA}

Siagian,N. 2003. Potensi dan pemanfaatan Mucuna bracteata sebagai penutup tanah di perkebunan karet. Warta pusat penelitian karet. Vol 24, No.1 Hal 5-12.

Chua, C. K. Ong dan Zainuriah. 2007. Kulim's experiences with establishing Mucuna bracteata under oil palm. Mucuna bracteata; A Cover Crop and Living Green Manure (Goh, K J and Chiu, S B eds.). Agricultural Crop Trust.p. 85-85.

Siagian,N. dan R,.Tistama, 2005. Perbanyakan tanaman penutup tanah Mucuna bracteata. Warta perkaretan. Vol 24. No.1, Hal:25-36 Hardianti,.P.S. C.Hanum, dan Charloq .2014.
Daya kecambah dan pertumbuhan Mucuna bracteata melalui pematahan dormansi dan pemberian zat pengatur tumbuh giberalin (GA3). Jurnal Online Agroteknologi. Vol.2, No.2; Hal 630-644.

Sutopo,.L. 2002. Teknologi Benih. Fakultas Pertanian. Universitas Brawijya. PT. Raja Grafindo Persada. Jakarta

Hartutiningsih dan Utami. 1999. Manipulasi $\mathrm{KNO}_{3}$ dalam upaya meningkatkan perkecambahan biji palem merah (Chrystotachys iakka Becc). Prosiding Seminar Nasional Konservasi Flora Nusantara. Balai Pengembangan Kebun Raya. Lembaga Ilmu Pengetahuan Indonesia. Bogor

Mugnisjah,.W.Q dan A. Setiawan. 1990. Produksi Benih. Bumi Aksara dan Pusat Antar Universitas. IPB. Bogor

Sulaiman,.F dan Gozali,.K 2004. Pengaruh Pematahan dormansi terhadap perkecambahan benih dan pertumbuhan bibit keranji (Dialium indum L.) Jurnal Tanaman Tropika Vol 7 (2); Hal 78-84. 